\title{
PERTUMBUHAN DAN HASIL TANAMAN SAWI PADA BEBARAPA JENIS BOKASHI (Growth and Produce the Mustard at various type Bokashi)
}

\author{
Zulkarnain Sangadji \\ Fakultas Pertanian Universitas Al-Amin Muhammadiyah Sorong
}

\begin{abstract}
Abstrak
Gift fertilize the bokashi can be used as organic manure to fertilize the land;ground and improve the growth and also produce the crop. this Research target to see the growth and result of mustard crop at some of type bokashi. Research executed in garden of Attempt of Faculty Of Agriculture of University Al Amen Shove from July until August month 2009. This research represent the Single Factor attempt of Random Group Lenkap Device ( RKLT). Treatment consisted of the AO (Without Bokashi ), A1 (Bokashi Charcoal with the dose $60 \mathrm{~g} \mathrm{crop}^{-1}$ ), A2 ( Dusty Bokashi with the dose $60 \mathrm{~g}$ tanaman-1), A3 (Bokashi Charcoal and Dusty with the dose

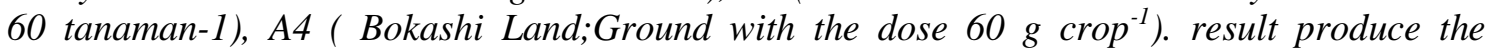
highest mustard crop in obtaining at Dusty treatment Bokashi 279, $55 \mathrm{~g}$ check $^{-1}$.
\end{abstract}

Keyword: Mustard, Produce, and Bokashi.

\section{PENDAHULUAN}

Tanaman Sawi (Brassica Junicea L.) termasuk tanaman sayuran yang sangat penting artinya dalam memperbaiki gizi makanan, terutama bagi sumber vitamin dan mineral, karena sayuran sangat berguna bagi kesehatan. Ada berbagai jenis sayur-sayuran sawi diantaranya adalah sawi hijau. Sawi hijau termsuk jenis sayuran daun yang merupakan salah satu sayuran yang banyak digemari orang karena rasanya enak dengan daun yang lembut serta mengandung vitamin A, B, dan Vicamin C (Anonimous, 2001).

Sejalan dengan perkembangan kota dan pertambahan penduduk di kota Sorong berpengaruh terhadap peningkatan kebutuhan hasil pertanian pada umumnya dan sayur-sayuran pada khususnya. Salah satu cara untuk meningkatkan produksi tanaman sawi adalah dengan cara pemupukan (Anonimous, 2001). Sarif (1985) menyatakan, untuk meningkatkan produksi sayuran dapat dilakukan dengan penambahan unsur hara kedalam tanah yang dapat berupa pupuk organik.

Susanto (2002) menyatakan bahwa pupuk organik pada dasarnya membatasi kemungkinan dampak negatif yang ditimbulkan olah pupuk anorganik seperti mengerasnya tanah akibat pemberian pupuk yang terus-menerus, rusaknya organisme pengurai tanah, rentangnya tanaman terhadap hama penyakit, pencucian unsur hara akibat kelarutan pupuk yang tinggi, dan dapat meracuni tanaman. Selain itu pupuk anorganik dapat meningkatkan residu kimia pada bahan pangan dan pakan ternak sehingga memberikan rasa yang kurang enak.

Salah satu pupuk organik yang dapat dijadikan alternatif adalah pupuk Bokashi. Menurut Anonimous (2002), Bokashi merupakan hasil fermentasi bahan organik dengan teknologi Effektif Mikroorganism-4 (EM-4) yang dapat digunakan sebagi pupuk organik untuk menyuburkan tanah dan meningkatkan pertumbuhan serta produksi tanaman. Menurut Susanto (2002), bahanbahan organik yang dapat digunakan sebagai bahan dasar pembuatan bokashi antara lain dedak, sekam padi, kulit kacang, jerami, ampas kelapa, rumput, serbuk gergaji, tepung jagung, tempurung kelapa, sampah rumah tangga, tepung ikan dan kotoran ternak.

\section{METODE PENELITIAN}

\subsection{Lokasi Penelitian}

Penelitian ini dilaksanakan di Kebun Percobaan Fakultas Pertanian Universitas Al Amin Sorong mulai bulan Juli sampai Agustus 2009. 


\subsection{Bahan dan Metode}

Bahan yang digunakan dalam penelitian ini berupa benih Sawi, pupuk Bokashi dan Dethene M45, alat yang digunakan adalah cangkul, sabit, ember, bambu, pengaris, kertas, timbangan dan alat tulis menulis.

\subsection{Rancangan Percobaan}

Penelitian ini merupakan percobaan Faktor Tunggal Rancangan Kelompok Lengkap Teracak (RKLT). Dimana rancangan ini cocok untuk percobaan di lahan pertanian dengan tingkat kesuburan tanah dan kemeringan lahan yang dapat diduga. (Gomes dan Gomes, 1995)

Derajat bebas untuk setiap sumber keragaman adalah :

$\begin{array}{ll}\text { Db. Umum } & : \mathrm{r} . \mathrm{t}-1 \\ \text { Db Kelompok } & : \mathrm{r}-1 \\ \text { Db. Perlakuan } & : \mathrm{t}-1\end{array}$

Dimana :

$$
\begin{aligned}
& \mathrm{t} \text { : Banyaknya Perlakuan } \\
& \mathrm{r} \text { : Banyaknya Kelompok }
\end{aligned}
$$

Sehingga d.b. galat dapat di hitung :

d.b. = d.b. umum - d.b. ulangan- d.b. perlakuan

Penelitian ini mengunakan lima (5) perlakuan dan tiga (3) kelompok, sehingga diperoleh 15 satuan percobaan. Perlakuan yang diberikan terdiri atas :

A0 : Tanpa Bokashi

A1 : Bokashi Arang dengan dosis $60 \mathrm{~g}$ $\operatorname{tanaman}^{-1}$

A2 : Bokashi Abu dengan dosis $60 \mathrm{~g}$ tanaman $^{-1}$

A3 : Bokashi Arang dan Abu dengan dosis 60 tanaman $^{-1}$

A4 : Bokashi tanah dengan dosis $60 \mathrm{~g}$ $\operatorname{tanaman}^{-1}$

\subsection{Pelaksanaan Penelitian.}

Pelaksanaan Penelitian ini dimulai dari tahap-tahap kegiatan, pengolahan tanah, persemaian dan penanaman, pemupukan, pemeliharaan tanaman, pengamatan dan pemanenan.

\section{Pengolahan Tanah}

Tanah yang digunakan terlebih dahulu dibersikan dari rerumputan, kemudian dicangkul sedalam kurang lebih $25-30 \mathrm{~cm}$ hingga menjadi gembur. Kemudian dibuat bedengan atau petakan, parit keliling dan parit antar petakan sesuai dengan ukuran yang telah ditentukan, pengolahan tanah dilakukan 2 minggu sebelum tanam.

\section{Persemaian dan Penanaman.}

Benih sawi langsung disemaikan dalam plstik kecil ukuran 7 x $9 \mathrm{~cm}$. Sebelum benih disemaikan, polibag diisi tanah yang sudah diayak dan ditambah sedikit pupuk kandang. Setelah tanaman berumur 14 hari dan sudah berdaun 4 sampai 5 helai, bibit siap untuk ditanam pada petakan, dengan jarak tanam 20 x $20 \mathrm{~cm}$. Penanaman dilakukan pada sore hari, dimana sebelum dan sesudah penanaman dilakukan penyiraman.

\section{Pemupukan.}

Pemupukan dilakukan pada setiap lubang tanam sesuai dengan perlakuan.

\section{Pemeliharaan.}

Pemeliharaan tanaman meliputi penyiraman, penyiangan serta pengendalian hama dan penyakit sesuai dengan keadaan dilapangan.

\section{Pengamatan.}

Parameter pengamatan dilakukan setiap 7 hari sekali, meliputi :

a. Tinggi Tanaman $(\mathrm{cm})$.

Pengamatan tinggi tanaman dilakukan 7 hari sekali yaitu mulai dari saat tanaman berumur 7 hari setelah tanam (HST) dan berakhir saat dicapai tinggi tanaman maksimum/tanaman menjelang panen. Pengukuran dilakukan dari permukaan tanah sampai bagian tanaman tertinggi.

b. Jumlah Daun (helai).

Pengamatan dilakukan terhadap daun yang telah membuka sempurna dan berwarna hijau.

c. Bobot Basah Brangkasan per tanaman $(\mathrm{g})$.

Bobot Basah Brangkasan per tanaman ditimbang pada saat panen. Penimbangan dilakukan tanpa mengikut sertakan akar tanaman

\section{Pemanenan}

Pemanenan dilakukan secara serentak untuk semua tanaman pada umur 4 minggu setelah tanam

\section{HASIL DAN PEMBAHASAN}

\subsection{Tinggi Tanaman}

Hasil analisis statistik menunjukkan bahwa pada umur 7 hari setelah tanam 
ISSN 1979-7540

(HST) dan 28 hari setelah tanam (HST) tidak memberikan pengaruh yang nyata $(\mathrm{P}=$ 0.05). Sedangkan pada umur 14 hari setelah tanam memberikan pengaruh yang sangat nyata $(P=0.01)$ dan pada umur 21 hari setelah tanam memberikan pengaruh yang nyata $(P=0.05)$. Rata-rata tinggi tanaman sawi yang diperoleh dari hasil pengukuran pada umur 7 samapai 28 hari setelah tanam disajikan pada tabel 1 .

Tabel 1. Rata-rata Tinggi Tanaman Sawi

\begin{tabular}{lllll}
\hline $\begin{array}{l}\text { Perlak } \\
\text { uan }\end{array}$ & \multicolumn{4}{l}{ Umur Pemberian Bokhasi } \\
\cline { 2 - 5 } & $7 \mathrm{HST}$ & $14 \mathrm{HST}$ & $21 \mathrm{HST}$ & 28 \\
$\mathrm{VO}$ & 11.33 & $12.83 \mathrm{~b}$ & $14.38 \mathrm{~b}$ & 18.27 \\
$\mathrm{~V} 1$ & 12.63 & $20.29 \mathrm{a}$ & $23.47 \mathrm{a}$ & 22.47 \\
V2 & 13.39 & $20.13 \mathrm{a}$ & $25.80 \mathrm{a}$ & 27.35 \\
V3 & 13.34 & $19.33 \mathrm{a}$ & $24.74 \mathrm{a}$ & 26.38 \\
V4 & 13.34 & $19.54 \mathrm{a}$ & $24.43 \mathrm{a}$ & 26.02 \\
BNT & tn & 2.37 & 4.9 & tn \\
\hline
\end{tabular}

Keterangan :

Angka yang diikuti huruf yang sama pada kolom yang sama tidak berbeda nyata pada uji Beda Nyata Terkecil $\alpha=0,05$; tn $=$ tidak berbeda nyata.

Pemberian jenis bokashi memberikan hasil tinggi tanaman terbaik pada semua umur pengamtan bila dibandingkan dengan tampa pemberian bokashi (VO). Rata-rata tinggi tanaman yang ditunjukkan pada tabel 1 ditampilkan pada gambar 1, 2, 3 dan 4 dibawah ini.

Pemberian bokashi abu menghasilkan tinggi tanaman tertinggi yaitu $27,35 \mathrm{~cm}$ (tabel 2). Hal ini diduga bokashi arang mampu menyediakan unsur hara yang dapat meningkatkan pertumbuhan tanaman. hal ini disebabkan bokashi yang diberikan pada tanaman mengandung sejumlah bahan organik yang dibutuhkan untuk pertumbuhan dan perkembangan tanaman. Bahan organik berpangaruh menurunkan bobot volume tanah, meningkatkan porositas, dan permeabilitas tanah.
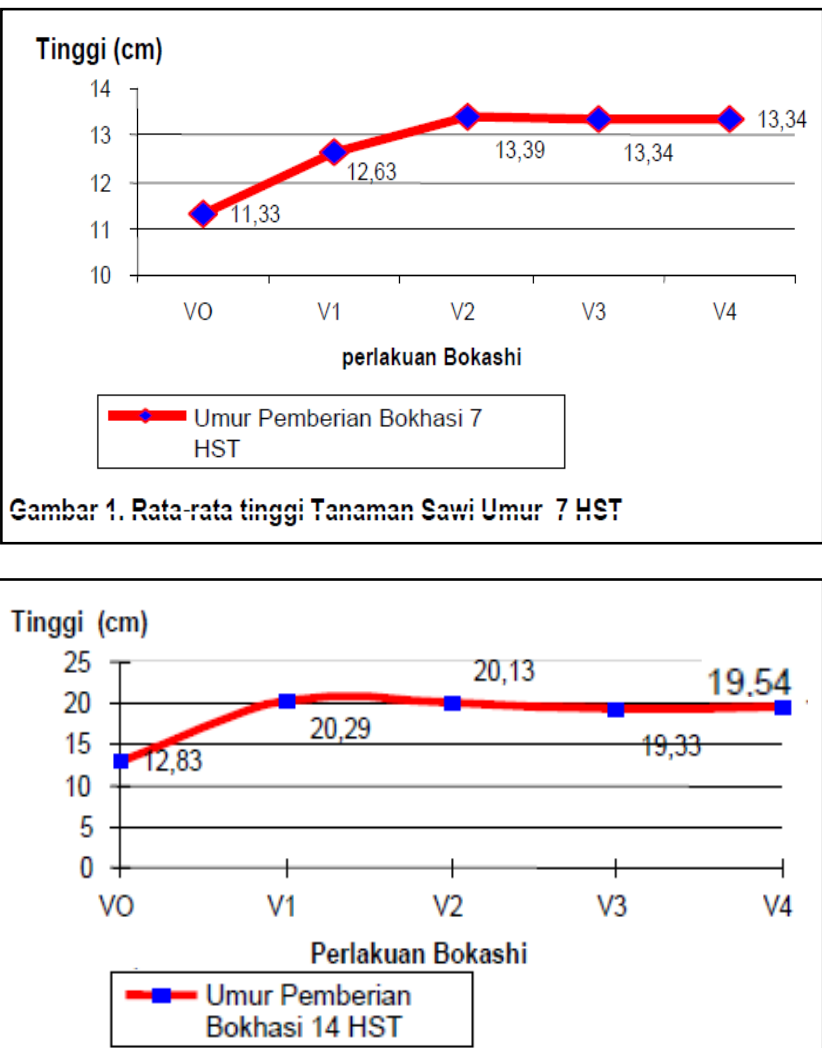

Gambar 2. Rata-rata Tinggi Tanaman Sawi Umur 14 HST

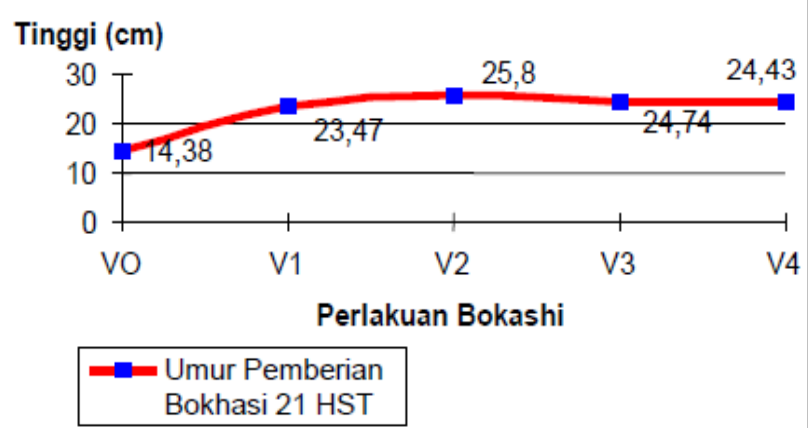

Gambar 3. Rata-rata Tinggi Tanaman sawi Umur 21 HST

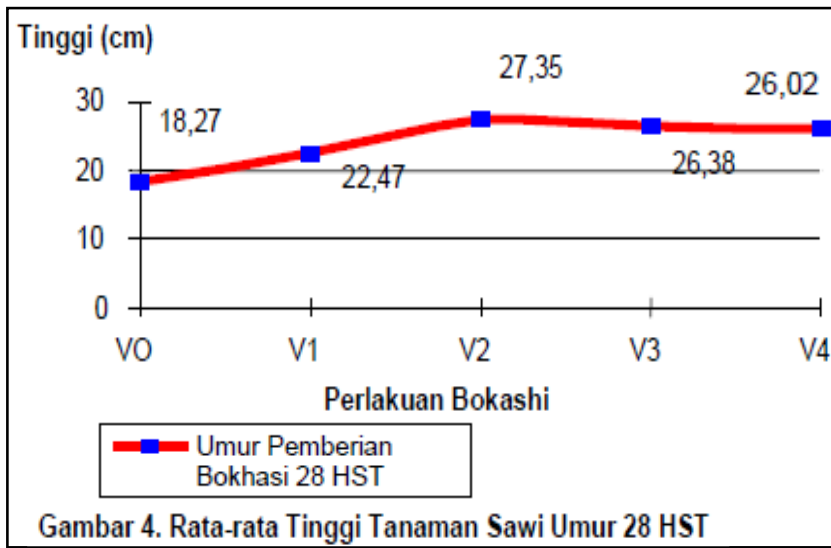


Ditambahkan lebih jauh oleh Susanto (2002), bahwa EM-4 yang digunakan dalam pembuatan bokashi dapat memperbaiki kondisi lingkungan fisik, kimia dan biologi tanah serta menekan pertumbuhan hama dan penyakit tanaman. Menurut Higa (1993), bahwa melalui peningkatan populasi mikroorganisme yang menguntungkan yang terdapat dalam EM-4 cendrung menekan mikroorganisme yang merugikan di dalam tanah, maka dengan sendirinya akan membantu dan memperpanjang kelangsungan hidup mikroorganisme yang lain yang menguntungkan dalam tanah.

\section{Jumlah Daun}

Hasil analisis statistik menunjukkan bahwa pada umur $7,14,21$ dan 28 hari setelah tanam tidak berpengaruh nyata $\mathrm{P}$ (0.05). Rata - rata Jumlah daun yang diperoleh dari hasil pengukuran disajikan pada tabel 2. Perlakuan jenis bokashi membrikan dampak yang baik pada semua umur pengamatan dibandingkan dengan tanpa pemberian bokashi (table 2). Rata-rata jumlah daun pada umur 7, 14, 21 dan 28 hari setelah tanam disajikan pada gambar 5, 6, 7 dan 8 .

Tabel 2. Rata-rata Jumlah Daun..Sawi

\begin{tabular}{lllll}
\hline \multirow{2}{*}{$\begin{array}{l}\text { Perla } \\
\text { kuan }\end{array}$} & \multicolumn{4}{l}{ Umur Pemberian Bokashi } \\
& 7 HST & 14 & 21 HST & 28 \\
\hline VO & 0.7836 & 0.9214 & 0.9700 & 1.0006 \\
V1 & 0.8323 & 0.9773 & 1.0364 & 1.0760 \\
V2 & 0.8228 & 0.9750 & 1.0533 & 1.7867 \\
V3 & 0.7981 & 0.9615 & 1.0267 & 1.0589 \\
V4 & 0.7981 & 0.9616 & 1.0619 & 1.0048 \\
\hline
\end{tabular}

\footnotetext{
Berdasarkan analisis sidik ragam bahwa perlakuan bokashi tidak menunujukkan perbedaan yang nyata pada semua pengamatan. Jumlah daun tanaman sawi tertinggi diperoleh pada perlakuan bokashi abu (V2) . Hal ini diduga kandungan unsur hara $\mathrm{N}$ yang terkandung dalam bokashi abu tersedia secara cukup dalam pertumbuhan vegetatif. dikemukan oleh Rao (1995), bahwa bakteri fotosintetik dapat menfiksasi $\mathrm{N}$ (gas (N2) di udara.
}

Fiksasi N2 bebas dari udara dengan bantuan bakteri fotosintetik akan meningkatkan kadar nitrogen yang tersedia dalam tanah yang dibutuhkan oleh pertumbuhan tanaman (Sutedjo, et.al., 1991). Nitrogen memiliki peran penting dalam proses pertumbuhan vegetatif seperti pembentukan hijau daun, ini dibutuhkan dalam proses fotosintesis. Apabila unsur ini cukup tersedia, maka proses guna menghasilkan fotosintat akan berjalan dengan baik dan pada gilirannya pertumbuhan tanaman tumbuh subur (Anonimous, 2001).

\section{Berat Segar Tanaman Sawi}

Hasil analisis Sidik ragam menunjukan bahwa berat segar daun tanaman sawi berpengaruh nyata. Terlihat perlakuan jenis bokashi menghasilkan berat segar tanaman sawi yang lebih baik dibanding tanpa pemberian bokashi (tabel 3). Rata-rata berat segar daun tanaman sawi pada akhir pengamatan disajikan pada tabel 3. Berat segar daun pada tabel 3 disajikan pada gambar 9 .

Tabel 3. Rata - Rata Berat Segar Tanaman Sawi

\begin{tabular}{ll}
\hline Perlakuan & $\begin{array}{c}\text { Berat } \\
\text { Tanaman Sawi }\end{array}$ \\
\hline A0 & $71.65 \mathrm{~b}$ \\
A1 & $212.22 \mathrm{a}$ \\
A2 & $270.55 \mathrm{a}$ \\
A3 & $212 \mathrm{a}$ \\
A4 & $244.22 \mathrm{a}$ \\
BNT & $90.92 \mathrm{a}$ \\
\hline
\end{tabular}

Keterangan :

Angka yang diikuti huruf yang sama pada kolom yang sama tidak berbeda nyata pada uji Beda Nyata Terkecil $\alpha=0,05$

Hasil analisis sidik ragam menunjukkan bahwa pemberian berbagai bokashi berbeda nyata. Sedangkan berat segar tanaman sawi tertinggi diperoleh pada perlakuan bokashi abu (A2) sebesar 270, 55 g.. Hal ini diduga $\mathrm{N}$ yang diberikan ke tanah dapat menyebabkan kapasitas pertukaran yang tinggi, baik terhadap kation maupun anion sehingga struktur tanah lebih sesuai dan dapat dimanfaatkan oleh tanaman secara langsung. Ini karena. pupuk nitrogen cendrung meningkatkan proses di atas tanah 
dan memberikan warna hijau serta berperan sebagai penyusun klorofil (Lingga dan Marsono, 2002). Selain itu, menurut Susanto (2002), dijelaskan bahwa perbedaan jenis bahan organik memberikan pengaruh yang berbeda pula terhadap kondisi tanah. Dijelaskan lebih jauh bahwa abu mengandung seluruh unsur hara yang diserap dan diperlukan oleh tanaman kecuali unsur $\mathrm{H}$ dan $\mathrm{O}$.

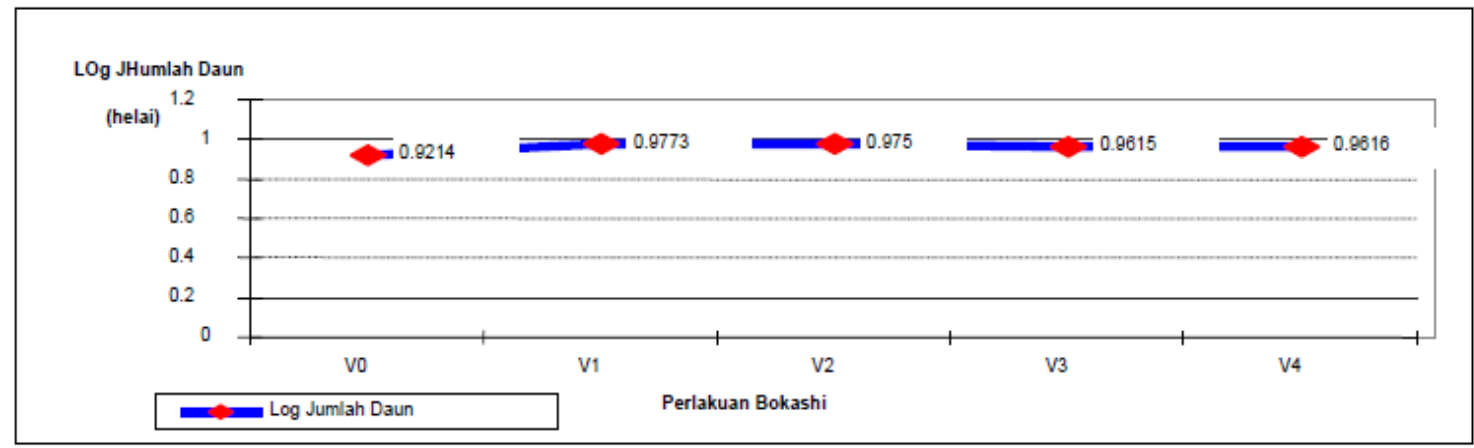

Gambar 5. Log Rata-Rata Jumlah Daun (7 HST)

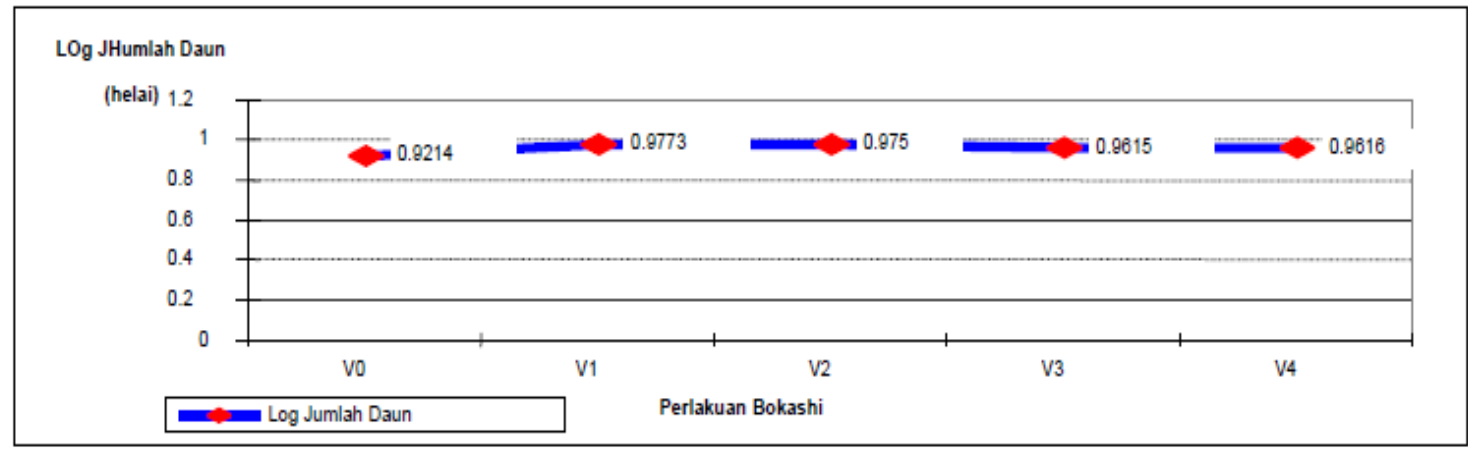

Gambar 6. Log Rata-Rata Jumlah Daun (14 HST)

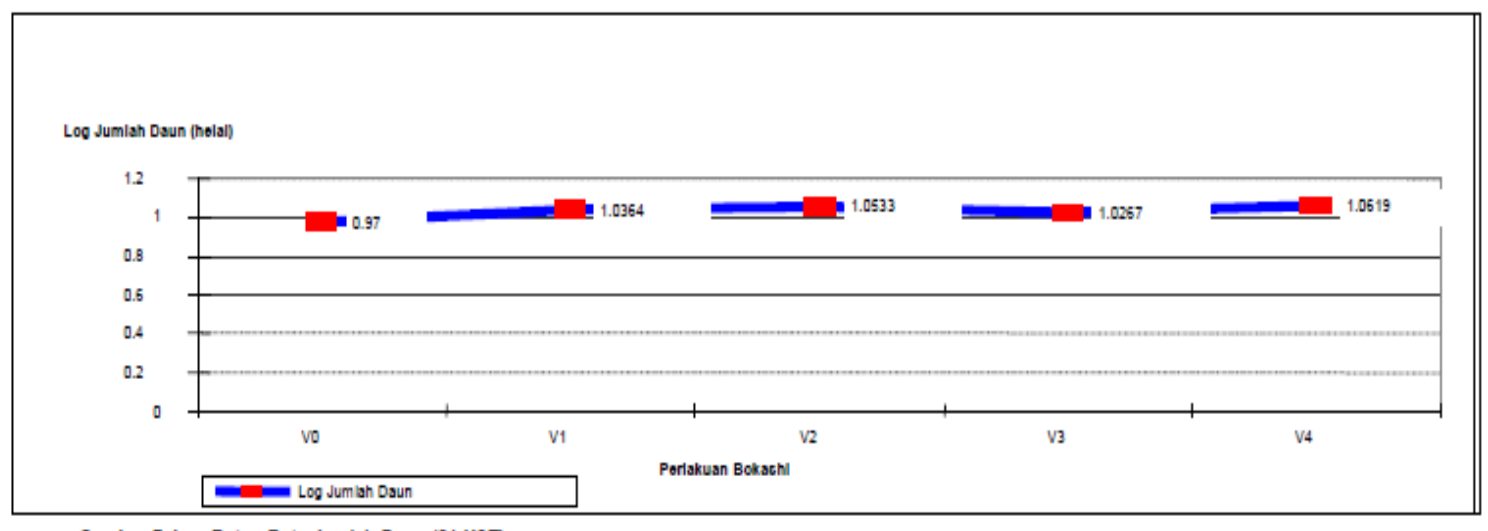

Gambar 7. Log Rata - Rata Jumlah Daun (21 HST) 
ISSN 1979-7540

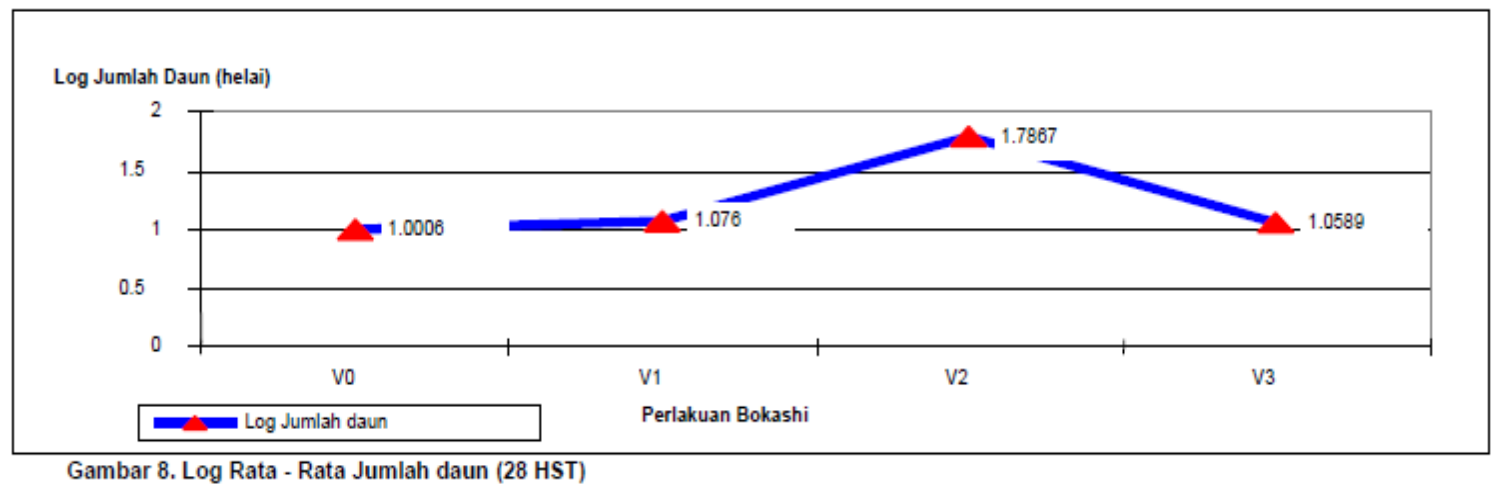

Rog Rata - Rata Jumlah daun (28 HST)

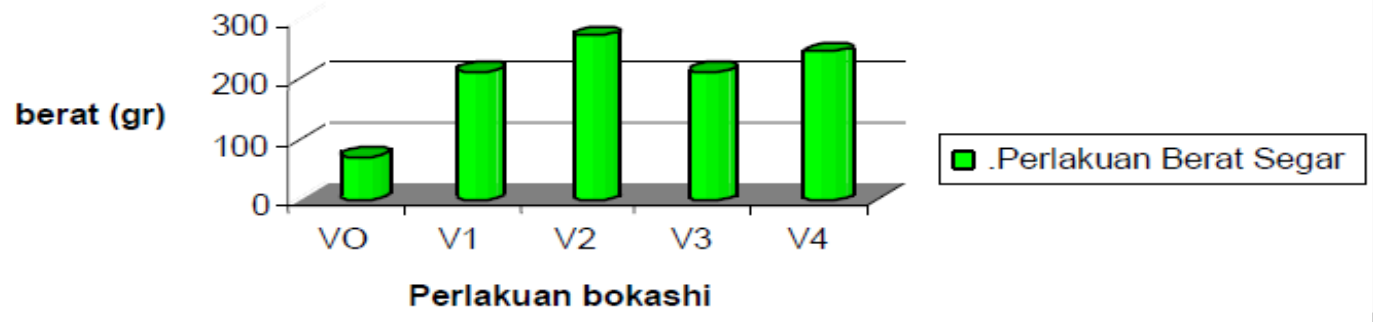

Gambar 9. Rata-rata Berat Segar tanaman sawi

\section{KESIMPULAN}

1. Perlakuan bokashi dengan campuran (arang, abu, arang-abu dan tanah) memberikan pengaruh yang sangat nyata untuk tinggi tanaman pada umur 14 dan 21 hari setelah tanam. Rata-rata tinggi tanaman tertinggi pada akhir pengamatan ditunjukkan oleh perlakuan Bokashi arang (A2) yaitu $27,35 . \mathrm{cm}$.

2. Jumlah daun untuk semua umur pengamatan tidak memberikan pengaruh yang nyata. Rata-rata jumlah daun terbanyak ditunjukkan oleh perlakuan bokashi abu (A2) yaitu 1.7867 halai

3. Perlakuan bokashi untuk berat segar tanaman sawi memberikan pengaruh yang nyata. Rata-rata terberat tanaman sawi ditujukkan olah perlakuan bokashi arang (A2) yaitu 279, 55 gram

\section{DAFTAR PUSTAKA}

Anonimous, 2001. Petunjuk praktis Bertanam Sayuran, Penerbit Yayasan Kanisius. Yogyakarta.

Anonimous, 1999. Pedoman penggunaan EM bagi Negar-negara Asia Pasifik. Nature Agriculture Ntework (APNAN). Badab Pendidikan dan
Anonimous, 2000. Kumpulan makalah" Worksohop Florikum 5" Malang 6 dan 7 Nopember 2000. Fakultas Pertanian Universitas Brawijaya. malang.

Foth, 1994. Dasar-dasar Ilmu tanah. Edisi Keenam. Airlangga. malang.

Gadner, P.F.R., Brent Pearce dan Roger L. Mitcel, 1991. Fisiologi Tanaman Budidaya. Universitas Indonesia. Jakarta.

Gomes.A.A. dan Gomes A.k. 1995. Prosedur Statistik untuk Penelitian Pertanian, Penerbit Universitas Indonesia. Jakarta 698 halm

Haryadi, 2001. Pengantar Agronomi. PT. Gramedia. Jakarta. 85 hal.

Hendro Sunaryo dan Rismunandar, 1984. Kunci Bercocok Tanam Sayuran di Indonesia. Penerbit CV. Sinar Baru. Bandung.

Maradjo. M, 1997. Tanaman Sayuran. Penerbit dan Pencetak PT. Karya Nusantara,. Jakarta. 47 hal.

Pinus Lingga. 1986. Petunjuk Penggunaan Pupuk. Fakultas Pertanian Universitas Brawijaya Malang.

Rakmat Rukmana, 1994. Bertanam Petsai dan Sawi. Penerbit Kanisius. IKAPI. 15-24 hal. 
Saifudin Sarif, 1985. Kesuburan Tanah dan Pemupukan. Penerbit Pustaka Buana. Bandung. 24 hal.

Sutanto R, 2002. Penerapan Pertanian Organik "Permasyarakatan dan Pengembangannya". Kanisius Yogyakarta.

Warsito, 2001. Produksi Tanaman Sayuran. Penerbit PT. Soeroengen. Jakarta. 